\title{
Why rename things?
}

\section{Ralph A. Lewin}

A an acquisitive small boy, when my pockets became too stuffed and the drawers of my desk could be opened only with difficulty, my father made me empty everything and sort it into categories: acid drops with aniseed balls, matchboxes with chrysalids, solder splashes with bits of lead, farthings with sous, and so on. In due course it comes naturally to humans to sort, categorize and name things. For ready retrieval, names can be alphabetized: fortunately, the order of letters is immutable.

Names can be descriptive, but where possible they too should be immutable for distinction and retrieval purposes. However stupid your neighbour, he's still Homo sapiens. A bald baby called Melanie (from the Greek word for black) may grow up as a blonde, but her name does not usually change on that account. John Smith may work in an office, and Bill Clark may shoe horses, but ordinarily $\mathrm{Mr} \mathrm{S}$. and $\mathrm{Mr}$ C. retain their names unchanged. That is why Linnaeus, in the middle of the eighteenth century, arranged that all animals and plants should have fixed binomials. What in previous centuries could have been Rosa europaea spinosissima floribunda alba fragrans (which would have described it) had its name fixed
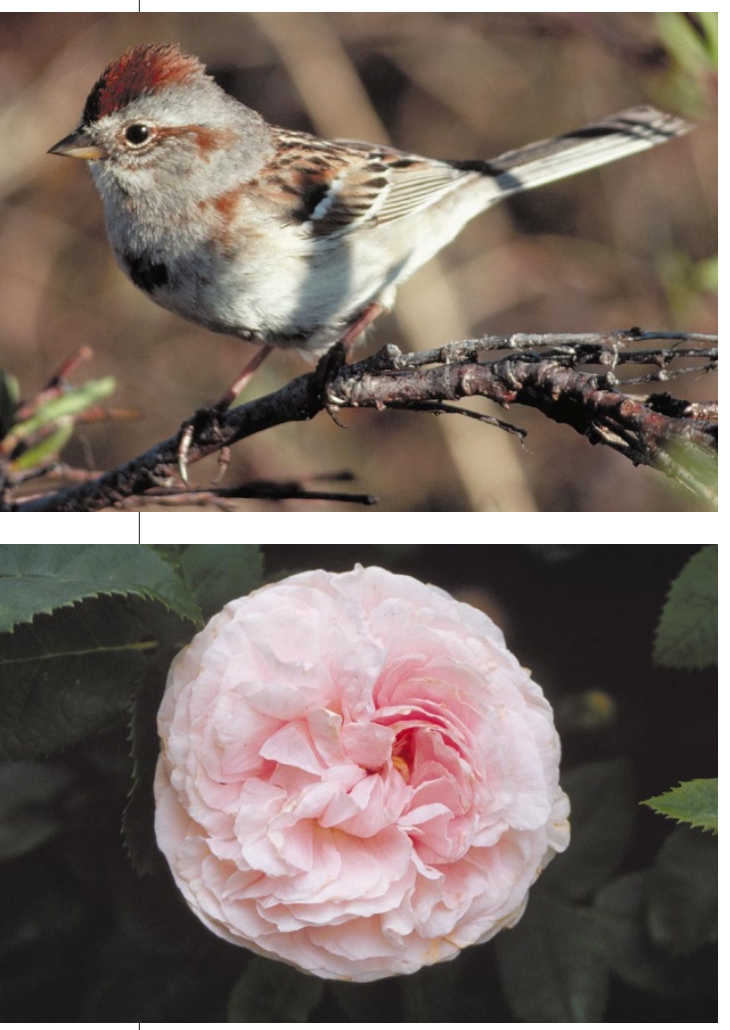

Widely accepted names enhance identification. succinctly as Rosa alba L. (for Linnaeus), even if it throws a pink variant. Even mistaken names - for instance, the North American beach vetch, Lathyrus japonica - are to be retained formally and technically.

Unfortunately, some microbiologists, who seem not to understand this neat idea, follow the medieval practice in describing, for instance, a little pink bacterium that turns paper mushy as something far too cumbersome, like Microrhodobacillobacter cellulosolytica. Entomologists, coping with a plethora of organisms among, say, beetles, tend to go in for neater names, such as Ips. (Microbiological neotaxonomists please note.) Incidentally, I think it's a good idea to spell out the names of genera on first use, as prescribed by the editors of Nature. For years I studied algae such as Chlamydomonas elegans without knowing that, among worm geneticists, C. elegans would refer to a completely different creature (although I don't think that either is particularly elegant).

Now that molecular biologists are producing phylogenetic trees (which, when congruent, we must consider irrefutable evidence for evolutionary pathways) a host of new problems arise. Because crocodiles are believed to be more closely related to birds than they are to turtles, for example, are sparrows just feathered reptiles, and does ornithology become merely a branch of herpetology? Hippos may be closer to whales than they are to their fellow ungulates such as pigs, so should librarians move hippo books down among the cetaceans? The lobe-finned coelacanth Latimeria is closer to humans than it is to herrings - so what price ichthyology? It is indeed a kettle of fish.

When it comes to higher orders, the plot thickens. Although we used to divide living things into plants and animals, some scientists have decreed that algae and fungi are not to be considered as plants. Their dictionaries told them that the Greek word for plant is phyton, so they renamed the Rhodophyta as Rhodophycophyta and the Cyanophyta as Cyanophycophyta. But stop a minute — if we synonymize prokaryotes with bacteria, then these blue-green microbes become Cyanobacteria. Moreover, since they can carry out photosynthesis, should we then call them photosynthetic bacteria? Traditionally, the latter don't evolve oxygen, and the bluegreens do. Hence they are neither phytoplankton nor phycoplankton, but maybe bacterioplankton. (Recently someone has thought up, and used, alas, the term Cyanoprokaryota.)

By similar arguments, the prokaryotic Actinomycetes, to be excluded from the eukaryotic fungi (mycetes), should be renamed Actinobacteria. And should all vas-

\section{Taxonomic classification}

"Are sparrows just feathered reptiles, and does ornithology become merely a branch of herpetology?"

cular plants, having indubitably sprung from green algal ancestors, be now classified as highly differentiated members of the Chlorophyta?

Some scientists have decreed that fungi cannot have flagellated stages; so whereas rusts and smuts, like mushrooms, remain classed as fungi, the potato blight, for instance, has to go in with the algae. What criteria delimit algae, when molecular data now indicate that the brown algal kelps are closer to animals than they are to, say, the red what's-its-names? And if the Archaea are so clearly unrelated to, say, Escherichia coli, as they branch off so low in phylogenetic trees, should we stop calling them bacteria (as some claim), moving them from bacteriology into a separate discipline: archaebacteriology or (even worse) archaeology?

Some of our colleagues, with little Latin and less Greek, have messed with the terminology of organs and organelles, too. Because wings were evolved by birds millions of years after they evolved among insects, and are unquestionably dissimilar in development and structure, then, not being homologous, they should be given a separate name - perhaps flapopodia, just as the flagella of algae, being wholly dissimilar in size and structure from the flagella of bacteria, have been renamed undulipodia. And then what should we call the Flagellata?

Actually, when it could be a matter of life and death, taxonomists in the medical profession do bypass molecular data that may indicate only a tiny proportion of genes distinguishing a pathogen from a harmless gut symbiont. Although they are probably indistinguishable under the microscope, the dangerous Vibrio cholerae is nominally distinguished from its benign cousins in the same genus.

Without denying the value of objective scientific data, unless they be demanded by expediency, I see no real benefit from adopting many such proposed taxonomic rearrangements or name changes. (Think back to $\mathrm{Mr}$ Clark and Mr Smith.) They muddle our language, and could introduce confusion in our libraries. Let's stick to widely accepted names and classifications whenever possible.

Ralph A. Lewin is in the Scripps Institution of

Oceanography, University of California, San Diego, California 92093-0202, USA.

\section{FURTHER READING}

Knapp, S. What's in a name? Nature 408, 33 (2000). 